\title{
Spermatozoon ultrastructure in two monorchiid digeneans
}

\author{
Yann Quilichini ${ }^{\text {Corresp.. }}{ }^{1}$ ， Abdoulaye J S Bakhoum ${ }^{1,2}$, Jean-Lou Justine ${ }^{3}$ ， Rodney A Bray ${ }^{4}$, Cheikh T Bâ ${ }^{2}$, \\ Bernard Marchand ${ }^{1}$ \\ ${ }^{1}$ GEM - Service d'Etude et de Recherche en Microscopie Electronique (SERME), UMR 6134 - SPE, CNRS - University of Corsica, Corte, Corsica, France \\ 2 \\ 3 ISYEB, Institut de Systématique, Évolution, Biodiversité (UMR7205 CNRS, EPHE, MNHN, UPMC), Muséum National d'Histoire Naturelle de Paris, Sorbonne \\ Universités, Paris, France \\ 4 Department of Life Sciences, National History Museum of London, London, United Kingdom \\ Corresponding Author: Yann Quilichini \\ Email address: quilichini@univ-corse.fr
}

Spermatological characteristics of species from two monorchiid genera, Opisthomonorchis and Paramonorcheides, have been investigated, for the first time, by means of transmission electron microscopy. The ultrastructural study reveals that the mature spermatozoon of Opisthomonorchis dinema and Paramonorcheides selaris share several characters such as the presence of two axonemes of different lengths showing the $9+$ " 1 " pattern of the Trepaxonemata, a nucleus, two mitochondria, two bundles of parallel cortical microtubules, external ornamentation of the plasma membrane, spine-like bodies, granules of glycogen and similar morphologies of the anterior and posterior extremities.

The slight differences between the male gamete of $O$. dinema and $P$. selaris are the length of the first axoneme and the position of the second mitochondrion. This study also elucidates the general morphology of the spermatozoon in all monorchiid species described so far, which corresponds to a unique spermatozoon type. Other interesting finds concern the spermatological similarities between monorchiid spermatozoa and the mature spermatozoon reported in the apocreadiid Neoapocreadium chabaudi. These similarities allow us to suggest a close phylogenetical relationship between the Monorchiidae and the Apocreadiidae, although more studies are needed, especially in the unexplored taxa. 
1 Spermatozoon ultrastructure in two monorchiid digeneans

2

3 YANN QUILICHINI ${ }^{1, *}$, ABDOULAYE J.S. BAKHOUM ${ }^{1,2}$, JEAN-LOU JUSTINE $^{3}$, RODNEY $^{2}$

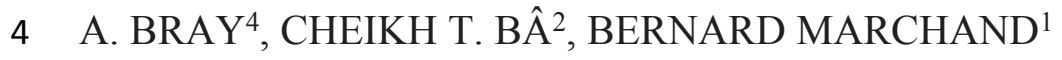

5 1UMR 6134 - SPE, CNRS - Università di Corsica, SERME Service d'Étude et de Recherche en

6 Microscopie Électronique, 20250 Corte, Corsica, France

$7 \quad{ }^{2}$ Laboratory of Evolutionary Biology, Ecology and Management of Ecosystems, Cheikh Anta

8 Diop University of Dakar, B.P. 5055, Dakar, Senegal

9 3ISYEB, Institut de Systématique, Évolution, Biodiversité (UMR7205 CNRS, EPHE, MNHN,

10 UPMC), Muséum National d'Histoire Naturelle, Sorbonne Universités, CP 51, 55 rue Buffon,

1175231 Paris cedex 05, France

$12{ }^{4}$ Department of Life Sciences, Natural History Museum, Cromwell Road, LondonSW7 5BD, 13 United Kingdom

*Corresponding author: Yann Quilichini, UMR 6134 - SPE, CNRS - Università di Corsica,

SERME Service d'Étude et de Recherche en Microscopie Electronique, 20250 Corte, Corsica, France; Email: quilichini@univ-corse.fr 


\section{ABSTRACT}

20 Spermatological characteristics of species from two monorchiid genera, Opisthomonorchis and

21 Paramonorcheides, have been investigated, for the first time, by means of transmission electron

22 microscopy. The ultrastructural study reveals that the mature spermatozoon of Opisthomonorchis

23 dinema and Paramonorcheides selaris share several characters such as the presence of two

24 axonemes of different lengths showing the $9+$ " 1 "' pattern of the Trepaxonemata, a nucleus, two

25 mitochondria, two bundles of parallel cortical microtubules, external ornamentation of the

26 plasma membrane, spine-like bodies, granules of glycogen and similar morphologies of the

27 anterior and posterior extremities. The slight differences between the male gamete of $O$. dinema

28 and P. selaris are the length of the first axoneme and the position of the second mitochondrion.

29 This study also elucidates the general morphology of the spermatozoon in all monorchiid species

30 described so far, which corresponds to a unique spermatozoon type.

31 Other interesting finds concern the spermatological similarities between monorchiid spermatozoa

32 and the mature spermatozoon reported in the apocreadiid Neoapocreadium chabaudi. These

33 similarities allow us to suggest a close phylogenetical relationship between the Monorchiidae

34 and the Apocreadiidae, although more studies are needed, especially in the unexplored taxa. 
38 The description of ultrastructural characteristics of the mature spermatozoon of the

39 Platyhelminthes, and in particular the Digenea, has recently proved to be an interesting tool for 40 phylogenetic purposes (Justine, 1995; Levron et al., 2010; Miquel et al., 2013; Bakhoum et al., 41 2012a, b; 2015a, b; Ndiaye et al., 2015a, b). The Monorchioidea comprise two families of 42 trematodes namely, the Lissorchiidae and the Monorchiidae (Bray, 2008). Among the latter, 43 which includes 40 valid genera (Madhavi, 2008), only two species, Monorchis parvus and 44 Helicometroides atlanticus (Levron, Ternengo \& Marchand, 2004; Diagne et al., 2015) have 45 been explored for spermatological characteristics. Moreover, the mature spermatozoon of $M$. 46 parvus and $H$. atlanticus exhibit some differences especially in their respective anterior 47 extremity.

48 The aim of this work was to bring more spermatological descriptions from two additional genera, 49 Opisthomonorchis and Paramonorcheides, in order to elucidate the general morphology of the 50 spermatozoon in the Monorchiidae. In addition, the mature spermatozoon of the monorchiids 51 was compared to those of the other digeneans with a brief comment on its phylogenetic 52 relevance. 
55 Fish were bought dead, but very fresh, at the fishmarket in Nouméa, New Caledonia. Specimens 56 of Opisthomonorchis dinema Bray \& Justine, 2013 were collected from the digestive tract of 57 Carangoides dinema Bleeker (Perciformes, Carangidae) caught off Nouméa, New Caledonia,

58 59 from the same fish specimen (MNHN JNC3224) as the paratypes of the species (Bray \& Justine, 2013). Specimens of Paramonorcheides selaris Lakshmi \& Madhavi, 2009 were collected from the digestive tract of Selar crumenophthalmus (Bloch, 1793) (Perciformes, Carangidae) caught off Nouméa, New Caledonia, on 10 Sept. 2009 (fish specimen MNHN JNC $3043)$.

Digenean specimens were fixed in cold $\left(4^{\circ} \mathrm{C}\right) 2.5 \%$ glutaraldehyde in $0.1 \mathrm{M}$ sodium cacodylate buffer at $\mathrm{pH} 7.2$, rinsed in $0.1 \mathrm{M}$ sodium cacodylate buffer at $\mathrm{pH} 7.2$, post-fixed in cold $\left(4^{\circ} \mathrm{C}\right)$ $1 \%$ osmium tetroxide in the same buffer for $1 \mathrm{~h}$, dehydrated in ethanol and propylene oxide series, embedded in Spurr resin and polymerized at $60{ }^{\circ} \mathrm{C}$ for $24 \mathrm{~h}$. Ultrathin sections $(60-90$ $\mathrm{nm}$ ) of the seminal vesicle were obtained on an ultramicrotome (Power tome PC, RMC Boeckeler $\left.{ }^{\circledR}\right)$. The sections were placed on 300 and 200 mesh copper grids and stained with uranyl acetate and lead citrate according to Reynolds (1963) methodology. To locate glycogen granules, the Thiéry technique (1967) was also used in several sections placed on gold grids.

All grids were examined on a Hitachi H-7650 transmission electron microscope, operating at an accelerating voltage of $80 \mathrm{kV}$, in the "Service d'Étude et de Recherche en Microscopie Électronique" of the University of Corsica (Corte, France). 
The organization of the mature spermatozoon of Opisthomonorchis dinema (Figs. 1,4) and

Paramonorcheides selaris (Figs. 2-4) is described after observations of cross- and longitudinal sections. Thus, in both monorchiid species four regions, with distinctive ultrastructural characteristics, are evident, from the anterior to the posterior spermatozoon extremities. The granules of glycogen present in $O$. dinema and $P$. selaris spem cells were detected by the cytochemical test of Thiéry (Fig. 3E for P. salaris).

Region I, corresponding to the anterior extremity of the mature spermatozoon, is characterized by the presence of the first axoneme accompanied by the anterior extremity of the second axoneme, cortical microtubules and external ornamentation of the plasma membrane. In O. dinema the anterior spermatozoon tip exhibits both anterior extremities of the axonemes, surrounded by a layer of cortical microtubules (about 26) and external ornamentation (Figs. 1A, B, 4I). In P. selaris longitudinal and cross-sections of the anterior spermatozoon tip show that it tapers to a point (Fig. 2A), and that it contains the anterior extremities of both axonemes and the cortical microtubules (about 26) (Fig. 2C) as well as exhibiting external ornamentation of the plasma membrane (Figs. 2B, C, 4I). In the middle part of the region I, when both axonemes are formed, spine-like bodies appear interrupting the external ornamentation of the spermatozoa of $O$. dinema and $P$. selaris (Figs. 1C, 2D, 4I). The posterior part of the region I is characterized,

96 for each species, by the presence of external ornamentation of the plasma membrane associated 97 with cortical microtubules and the first mitochondrion (Figs. 1D, E, 2E, 4I). No glycogen granule 98 have been highlighted by the Thiéry's method in this region. 
Region II corresponds to the transitional area before the nuclear region. For both $O$. dinema

100

101

102

103

104

105

106

107

108

109

110

111

112

113

114

115

116

117

118

119

120

121

and $P$. selaris spermatozoa, it is characterized by the absence of external ornamentation and the presence of the axonemes and the first mitochondrion (Figs. 1F, 2F, 4II). In addition, for each monorchiid species, the posterior part of the region II contains a reduced number of cortical microtubules: about 5 in $O$. dinema (Fig. 1G) and 13 in P. selaris (Fig. 2G). Only few granules of glycogen are observed in this region.

Region III exhibits several ultrastructural characteristics that distinguish the mature spermatozoa of $O$. dinema (Figs. 3a, 4IIIa) from those of $P$. selaris (Figs. 3b, 4IIIb):

- In the anterior part of the region III, the spermatozoon is characterized by the disorganization of the first axoneme in $O$. dinema (Figs. 1H, 4IIIa), whereas in P. selaris the two axonemes and the second mitochondrion are observed (Figs. 2H, 4IIIb).

- The middle part of the region III is characterized in $O$. dinema by the presence of only one axoneme, the nucleus, few cortical microtubules and the second mitochondrion (Figs. 1I,4IIIa). In contrast, in P. selaris, the second mitochondrion, the nucleus and few cortical microtubules were accompanied by the two axonemes (Figs. 2I, 4IIIb). Note that this part corresponds to the disorganization of the first axoneme in P. selaris (Figs. 2J, 4IIIb).

- In the posterior part of the region III, the second mitochondrion, accompanied by one axoneme, the nucleus and cortical microtubules is observed in both $O$. dinema (Figs. 1I, 4III) and in P. selaris (Figs. 3A, 4III).

This region is characterized, for the two species, by a high number of glycogen granules.

Region IV represents the posterior spermatozoon extremity. When the second mitochondrion disappears in both $O$. dinema and $P$. selaris mature spermatozoa, cross-sections exhibit only one axoneme, the nucleus and very few cortical microtubules (Figs. 1J, 3B, 4IV). Moreover, for each 
122 species, the second axoneme disorganizes exhibiting doublets and singlets of microtubules (Figs.

$1231 \mathrm{~K}, 3 \mathrm{C}$ ). Consequently, the posterior spermatozoon tips in $O$. dinema and $P$. selaris show only

124 the nucleus (Figs. 1L, 3D, 4IV).

125 For the two species, only few glycogen granules have been observed in the anterior part of this 126 region.

\section{DISCUSSION}

128 The mature spermatozoon described in Opisthomonorchis dinema and Paramonorcheides selaris 129 possesses two axonemes of the 9+" 1 " trepaxonematan pattern, two mitochondria, a nucleus, two 130 bundles of parallel cortical microtubules, an external ornamentation of the plasma membrane, 131 spine-like bodies and granules of glycogen. In addition to these ultrastructural characters, the 132 male gamete of $O$. dinema and $P$. selaris exhibits similar anterior and posterior spermatozoon 133 morphologies.

134 Within the Monorchiidae most of these spermatological characters were described previously in 135 Monarchus parvus and Helicometroides atlanticus (Levron, Ternengo \& Marchand, 2004; 136 Diagne et al., 2015). Thus, the characters of the mature spermatozoon, its anterior and posterior 137 morphologies were used here in comparative studies between the different species (Table 1).

139 General organisation of the mature spermatozoon in the Monorchiidae

140 From the anterior part to the posterior part of the gametes, six characteristics are presented here 141 to describe the architecture of the mature spermatozoa in Monorchiidae. Moreover, monorchiid 142 spermatozoa are compared to those reported from the other digenean species.

\section{3 - Type of axoneme}

144 The structure of the axoneme with 9+“1” pattern of Trepaxonemata (Ehlers, 1984) has been 
145 observed in $O$. dinema and $P$. selaris as described previously in $M$. parvus and H. atlanticus

146 (Table 1). A similar morphology of the axoneme has been reported in most digenean species

147 (Quilichini et al., 2011a; Foata et al., 2012; Miquel et al., 2013; Ndiaye et al., 2012, 2015a) with

148 the exception of schistosomes in which the $9+" 1 "$ special pattern was described and some

149 didymozoid species showing the 9+0 pattern (Justine \& Mattei, 1983; Justine, Jamieson \&

150 Southgate, 1993; Yang, Dong \& Jiang, 2003).

151 Their different length is another aspect related to axonemes. In both $O$. dinema and $P$.

152 selaris, the posterior extremity of the axoneme 2 is longer than that of the first one. Moreover,

153 the spermatozoon of $O$. dinema is distinguished by the first axoneme that does not reach the

154 nuclear region, while in $P$. selaris the first axoneme is observed in the nuclear area like in $M$.

155 parvus and H. atlanticus (Levron, Ternengo \& Marchand, 2004; Diagne et al., 2015).

$156 \quad-\quad$ Anterior spermatozoon morphology

157 The anterior spermatozoon extremity of $O$. dinema and $P$. selaris contains two axonemes, 158 cortical microtubules and external ornamentation of the plasma membrane. Within the 159 Monorchiidae, an anterior spermatozoon extremity showing two axonemes, cortical microtubules 160 and external ornamentation has been reported in Monorchis parvus (Levron, Ternengo \& 161 Marchand, 2004). Whereas in the other monorchiid species studied so far, namely H. atlanticus 162 (Diagne et al., 2015), only electron-dense material and two axonemes have been observed in the 163 anterior spermatozoon extremity.

164 Mature spermatozoa showing two axonemes and external ornamentation in their anterior 165 extremities have also been reported in spermatozoa belonging to some digenean species such as 166 the apocreadiid Neoapocreadium chabaudi (Kacem et al., 2010), the pronocephalids 167 Pleurogonius truncatus and Cricocephalus albus (Ndiaye et al., 2011, 2012) and the 
168 mesometrids Centroderma spinosissima and Wardula capitellata (Bakhoum et al., 2012b, 2013).

169 In the two latter families the presence of a lateral expansion is described in the anterior

170 spermatozoon extremity of the studied species.

171 Other types of spermatozoa showing two axonemes in their anterior extremities have been

172 reported in several digenean species such as the deropristid Deropristis inflata (Foata, Quilichini

173 \& Marchand, 2007), the omphalometrid Rubenstrema exasperatum (Bakhoum et al., 2011) or the

174 pleurogenids Pleurogenes claviger, Pleurogenoides medians and Prosotocus confusus (Miquel et

175 al., 2013).

$176 \quad-\quad$ External ornamentation and its location

177 In all monorchiid species studied, the presence of external ornamentation associated with cortical

178 microtubules has been observed in the anterior region of the spermatozoon as in most digenean

179 species (Justine \& Mattei, 1982; Miquel et al., 2006; Quilichini et al., 2007; Bâ et al., 2011;

180 Ndiaye et al., 2012, 2015a, b; Bakhoum et al., 2015a, b). However, the location of the external

181 ornamentation distinguishes the spermatozoa of $O$. dinema and $P$. selaris from those of other

182 digenean species. In fact, based on the diagram of the localization of the external ornamentation

183 established by Quilichini et al. (2011a), the mature spermatozoon of $O$. dinema and P. selaris

184 presents the type 1 of external ornamentation, i.e., located in proximal part of the anterior

185 spermatozoon region. It is also interesting to note that in both $O$. dinema and P. selaris, the

186 external ornamentation is extended from centriole level to the area containing the first

187 mitochondrion. Such disposition of the external ornamentation is also reported in the monorchiid

$188 M$. parvus but not in H. atlanticus (Table 1). This latter species seems to exhibit type 2 external

189 ornamentation according to the diagram of Quilichini et al. (2011a).

$190 \quad$ - Spine-like bodies 
191 Since their first description by Miquel, Nourrisson \& Marchand(2000) the spine-like bodies have

192 frequently been reported in the mature spermatozoon especially in its anterior part. In the male 193 gamete of $O$. dinema and $P$. selaris, spine-like bodies are present in the ornamented area 194 associated with cortical microtubules. Moreover, in both monorchiid species the morphology of 195 the spine-like bodies follows that reported in most digenean species i.e., appearance of a small 196 vesicle interrupting the external ornamentation of the plasma membrane (Miquel et al., 2006; 197 Quilichini et al., 2011b; Bakhoum et al., 2015b; Ndiaye et al., 2015a, b).

198 Within the Monorchiidae, the absence of spine-like bodies was mentioned in the male gamete 199 of M. parvus and H. atlanticus (Levron, Ternengo \& Marchand, 2004; Diagne et al., 2015) 200 (Table 1). Hence the spine-like bodies are described here, for the first time, in the mature 201 spermatozoon of monorchiid species.

202 Taking into account all these aspects, the presence or absence of spine-like bodies in the 203 Monorchiidae needs more ultrastructural investigations.

$204 \quad-\quad$ Number of mitochondria

205 The presence of mitochondria in the mature spermatozoon is considered as a plesiomorphic 206 character in the Digenea (Bakhoum et al., 2014) whereas in other groups, such as the Eucestoda, 207 the absence of mitochondria has been highlighted as a synapomorphy (Justine, 1991a). Besides 208 its interest in phylogenetic relationships, the other criterion related to mitochondria is their 209 number.

210 Based on many cross- and longitudinal sections, two mitochondria are evident in the mature 211 spermatozoon of $O$. dinema and $P$. selaris. The presence of two mitochondria have also been 212 reported in $M$. parvus, $H$. atlanticus (Table 1) and in several species belonging, for instance, to 213 the families Acanthocolpidae (Bakhoum et al., 2015a), Apocreadiidae (Kacem et al., 2010), 
214 Deropristidae (Foata, Quilichini \& Marchand, 2007) or Notocotylidae (Ndiaye et al., 2003, 215 2015b). Other digenean species possess one mitochondrion [e.g. Carmyerius endopapillus (Seck 216 et al., 2008), Wardula capitellata; (Bakhoum et al., 2012b)] or three mitochondria [(e.g. 217 Anisocoelium capitellatum (Ternengo et al., 2009), Euryhelmis squamula (Bakhoum et al., 218 2009].

219 In the present study, the position of the second mitochondrion is an ultrastructural 220 characteristic that distinguishes the mature spermatozoa of $O$. dinema from those of P. selaris, $H$. 221 atlanticus and M. parvus. The second mitochondrion appears after the disorganization of the first 222 axoneme in $O$. dinema, whereas in the remaining monorchiid the appearance of the second 223 mitochondrion is noted before the posterior extremity of the first axoneme.

\section{$224 \quad-\quad$ Posterior spermatozoon characters}

225 In Digenea the posterior spermatozoon extremity is morphologically variable and is, therefore, 226 valuable in the establishment of spermatozoon models (Quilichini et al., 2010; Ndiaye et al., 227 2015b; Bakhoum et al., 2012a, 2015a). In all monorchiid species described so far the posterior 228 spermatozoon extremity contains a nucleus as in $O$. dinema and $P$. selaris (Table 1). This 229 morphology of the posterior spermatozoon extremity is frequently reported in digenean (Kacem 230 et al., 2010, 2015a, b; Zhukova, Mordvinov \& Kiseleva, 2014; Quilichini et al., 2015) and 231 corresponds to the fasciolidean type or type 2 according to the diagram of Quilichini et al. 232 (2010).

233 Other types of posterior spermatozoon extremities have been reported in digenean species. This 234 is the case of mature spermatozoa exhibiting one axoneme as described in most microphalloid 235 species (Bakhoum et al., 2012a; Miquel et al., 2013; Bruňanská et al., 2014) and opisthorchioid 236 species (Quilichini et al., 2009; Foata et al., 2012; Zhukova, Mordvinov \& Kiseleva, 2014). In 
237 the other hand, in the families Opecoelidae and Opistholebetidae (Miquel, Nourrisson \&

238 Marchand, 2000; Levron et al., 2003, 2004b; Quilichini et al., 2010, 2011b), there are mature

239 spermatozoa showing only cortical microtubules in their posterior extremities.

240

241 Phylogenetic perspectives of ultrastructural characteristics

242 The ultrastructural differences observed in the spermatozoa are phylogenetically informative in 243 the Neodermata, particularly in the Cestoda and Monogenea (Justine 1991b, 1998, Levron et al., 244 2010). In the Digenea a large amount of spermatological data accumulated over the recent years 245 could serve as a complementary resource for understanding their phylogenetic relationships 246 (Quilichini et al., 2010; Miquel et al., 2013; Bakhoum et al., 2015a; Diagne et al., 2015).

247 The phylogenetic relationships in the Monorchiidae and its systematic placement within 248 the Digenea have been controversial. The Monorchiidae has been considered polyphyletic 249 because of the great diversity exhibited in the morphology of its members (Madhavi, 2008). The 250 most recent classification based on DNA sequences includes the Monorchiidae and Lissorchiidae 251 in the superfamily Monorchioidea (Bray, 2008), which was included in the new suborder 252 Monorchiata (Olson et al., 2003).

Here, the understanding of the relationships and phylogenetic affinities in Monorchiidae 254 are attempted with ultrastructural characteristics of the spermatozoa, although there still remain 255 some unexplored groups. The morphology of the spermatozoa described in $O$. dinema, P. selaris and other monorchiid species is similar in several points to that reported in the apocreadiid

257 Neoapocreadium chabaudi (Kacem et al., 2010). The main similarities concern (1) the type of 258 axoneme, (2) the morphology of both anterior and posterior spermatozoon extremities, (3) the 
259 presence of type 1 external ornamentation according to Quilichini et al. (2011a), (4) the two

260 bundles of parallel cortical microtubules and (5) the presence of spine-like bodies.

261 Besides these similarities, it is interesting to note that the systematic position of the

262 Apocreadiidae is unresolved. Some authors have grouped this family with the Haploporoidea and

263 Monorchioidea (Cribb et al., 2001). Whereas other researchers suggested the removal of the

264 Apocreadiidae from the Lepocreadioidea (see Bray \& Cribb, 2012). Thus, to our knowledge no

265 robust data are available to validate the phylogenetic position of the Apocreadiidae.

266 The present spermatological findings suggest, for the first time, a close relationship between the

267 Monorchiidae and the Apocreadiidae based on ultrastructural characteristics of their mature

268 spermatozoa. However, further studies are needed in order to support our hypothesis. Moreover,

269 ultrastructural studies in the Lissorchiidae (probably a sister group) are also needed to test their 270 close relationships with the Monorchiidae.

\section{Conclusion}

273 The mature spermatozoa of Opisthomonorchis dinema and Paramonorcheides selaris share

274 several ultrastructural features with those reported in Monorchis parvus and Helicometroides

275 atlanticus (Table 1). These similarities allow us to define the type of spermatozoon in the

276 Monorchiidae, which exhibits the following features:

277 - Presence of an anterior extremity showing two axonemes accompanied by cortical 278 microtubules and external ornamentation,

279 - Presence of the association "external ornamentation+cortical microtubules",

280 - Location of the external ornamentation corresponding to the type 1 according Quilichini

$281 \quad$ et al. (2011a), 
282

283

284

285

286

287

288

289

290

291

292

293

294

295

296

297

298

299

300

301

302

303

304

- Presence of two bundles of parallel cortical microtubules and two mitochondria,

- Posterior spermatozoon extremity containing only the nucleus according to Quilichini et al. (2010).

The model of mature spermatozoon described here for the monorchiid species is relatively similar to that reported to the apocreadiid Neoapocreadium chabaudi (Kacem et al. 2010). These similarities allow us to suggest a close relationship between the Monorchiidae and Apocreadiidae, although additional spermatological evidences are needed especially, from the unexplored taxa belonging to the families mentioned above and the Lissorchiidae.

The ultrastructural characteristics described in digenean and in particular, the Monorchiidae could be used as phylogenetic tools and when establishing spermatozoon models, given that they may allow the distinguishing of genera, families or superfamilies within the Digenea.

\section{REFERENCES}

Bâ CT, Ndiaye PI, Dione A, Quilichini Y, Marchand B. 2011. Ultrastructure of the spermatozoon of Holorchis micracanthum (Digenea: Lepocreadiidae), an intestinal parasite of Plectorhinchus mediterraneus (Pisces, Teleostei) in Senegal. Parasitology Research 109:10991106.

Bakhoum AJS, Bâ CT, Fournier-Chambrillon C, Torres J, Fournier P, Miquel J. 2009. Spermatozoon ultrastructure of Euryhelmis squamula (Rudolphi, 1819) (Digenea, Opisthorchioidea, Heterophyidae), an intestinal parasite of Mustela vison (Carnivora, Mustelidae). Revista Ibero-latinoamericana de Parasitología 1:37-45.

Bakhoum AJS, Bâ CT, Shimalov VV, Torres J, Miquel J. 2011. Spermatological characters 
305 of the digenean Rubenstrema exasperatum (Rudolphi, 1819) (Plagiorchioidea, 306 Omphalometridae). Parasitology Research 108:1283-1293.

307 Bakhoum AJS, Feliu C, Bâ CT, Miquel J. 2012a. Spermiogenesis and spermatozoon of the 308 liver fluke Mediogonimus jourdanei (Microphalloidea: Prosthogonimidae), a parasite of Myodes 309 glareolus (Rodentia: Cricetidae). Folia Parasitologica 59:32-42.

310 Bakhoum AJS, Kacem H, Neifar L, Miquel J. 2013. Ultrastructure of the spermatozoon of

311 Centroderma spinosissima (Stossich, 1886) (Digenea: Mesometridae) and its phylogenetic 312 potential. Tissue and Cell 45:428-33.

313 Bakhoum AJS, Ndiaye PI, Sène A, Bâ CT, Miquel J. 2012b. Spermiogenesis and 314 ultrastructure of the spermatozoon of Wardula capitellata (Digenea, Mesometridae), an intestinal 315 parasite of the sparid teleost Sarpa salpa in Senegal. Acta Parasitologica 57:34-45.

316 Bakhoum AJS, Quilichini Y, Justine J-L, Bray RA, Bâ CT, Marchand B. 2015a. 317 Ultrastructural study of sperm cells in Acanthocolpidae: the case of Stephanostomum murielae 318 and Stephanostomoides tenuis (Digenea). PeerJ 3, e744.

319 Bakhoum AJS, Quilichini Y, Justine J-L, Bray RA, Bâ CT, Marchand B. $2015 b$. 320 Neomultitestis aspidogastriformis Bray and Cribb, 2003 (Digenea, Lepocreadiidae): mature 321 spermatozoon and sperm morphologies in the Lepocreadioidea. Cell Biology International 322 39:799-807.

Bakhoum AJS, Quilichini Y, Miquel J, Feliu C, Bâ CT, Marchand B. 2014. Collyricloides massanae (Digenea, Collyriclidae): spermatozoon ultrastructure and phylogenetic importance. Parasite 21:59.

Bray RA. 2008. Superfamily Monorchioidea Odhner, 1911. In: Bray RA, Gibson DI, Jones A, 327 eds. Keys to the Trematoda, vol. 3. London: CAB International and The Natural History 
328 Museum, 143-144.

329 Bray RA, Cribb TH. 2012. Reorganisation of the superfamily Lepocreadioidea Odhner, 1905

330 based on an inferred molecular phylogeny. Systematic Parasitology 83:169-177.

331 Bray RA, Justine J-L. 2013. Three species of opisthomonorchiine monorchiids (Digenea) in

332 Carangoides spp. (Perciformes: Carangidae) from off New Caledonia, with a description of

333 Opisthomonorchis dinema n. sp. Systematic Parasitology 85:147-156.

334 Bruňanská M, Brázová T, Zhokhov AE, Poddubnaya LG. 2014. Ultrastructural features of

335 the spermatozoon and its differentiation in Brandesia turgida (Brandes, 1888) (Digenea, 336 Microphalloidea, Pleurogenidae). Parasitology Research 113:2483-2491.

337 Cribb TH, Bray RA, Littlewood DTJ, Pichelin SP, Herniou EA. 2001. The Digenea. In:

338 Littlewood DTJ, Bray RA, eds. Interrelationships of the Platyhelminthes. London: Taylor and 339 Francis, 168-185.

340 Diagne PM, Quilichini Y, Bâ CT, Ndiaye PI, Dione A, Marchand B. 2015. Ultrastructure of 341 the spermatozoon of Helicometroides atlanticus (Digenea, Monorchiidae), an intestinal parasite 342 of Parapristipoma octolineatum (Pisces, Teleostei) in Senegal. Tissue and Cell 47:198-204.

343 Ehlers U. 1984. Phylogenetisches System der Plathelminthes. Verhandlungen des 344 Naturwissenschaftlichen Vereins Hamburg, NF 27:291-294.

345 Foata J, Quilichini Y, Greani S, Marchand B. 2012. Sperm ultrastructure of the digenean 346 Aphallus tubarium (Rudolphi, 1819) Poche, 1926 (Platyhelminthes, Cryptogonimidae) intestinal 347 parasite of Dentex dentex (Pisces, Teleostei). Tissue and Cell 44:15-21.

348 Foata J, Quilichini Y, Marchand B. 2007. Spermiogenesis and sperm ultrastructure of 349 Deropristis inflata Molin, 1859 (Digenea, Deropristidae), a parasite of Anguilla anguilla. 350 Parasitology Research 101:843-52. 
351 Justine J-L. 1991a. Phylogeny of parasitic Platyhelminthes - a critical study of synapomorphies

352 proposed on the basis of the ultrastructure of spermiogenesis and spermatozoa. Canadian Journal 353 of Zoology 69:1421-1440.

354 Justine J-L. 1991b. Cladistic study in the Monogenea (Platyhelminthes), based upon a 355 parsimony analysis of spermiogenetic and spermatozoal ultrastructural characters. International 356 Journal for Parasitology 21:821-838.

357 Justine J-L. 1995. Spermatozoal ultrastructure and phylogeny of the parasitic Platyhelminthes. 358 Mémoires du Muséum National d'Histoire Naturelle 166:37-54.

359 Justine J-L. 1998. Spermatozoa as phylogenetic characters for the Eucestoda. Journal of 360 Parasitology 84:385-408.

361 Justine J-L, Jamieson BGM, Southgate VR. 1993. Homogeneity of sperm structure in six 362 species of Schistosomes (Digenea, Platyhelminthes). Annales de Parasitologie Humaine et 363 Comparée 68:185-187.

364 Justine J-L, Mattei X. 1982. Réinvestigation de l'ultrastructure du spermatozoïde 365 d'Haematoloechus (Trematoda: Haematoloechidae). Journal of Ultrastructure Research 8:322366332.

367 Justine J-L, Mattei X. 1983. A spermatozoon with two $9+0$ axonemes in a parasitic flatworm, 368 Didymozoon (Digenea: Didymozoidae). Journal of Submicroscopic Cytology and Pathology 369 15:1101-1105.

370 Kacem H, Bakhoum AJS, Neifar L, Miquel J. 2010. Spermiogenesis and spermatozoon 371 ultrastructure of the digenean Neoapocreadium chabaudi (Apocreadiidae), a parasite of Balistes 372 capriscus (Pisces, Teleostei). Parasitology International 59:358-366.

373 Kacem H, Ndiaye PI, Neifar L, Torres J, Miquel J. 2015a. Ultrastructure of the spermatozoon 
374 of the digenean Tergestia acanthocephala (Stossich, 1887) (Gymnophalloidea: Fellodistomidae):

375 an intestinal parasite of Belone belone gracilis (Pisces: Teleostei). Tissue and Cell 47:235-241.

376 Kacem H, Ndiaye PI, Neifar L, Torres J, Miquel J. 2015b. Spermatological characters of the

377 digenean Lecithostaphylus retroflexus (Molin, 1859) (Microphalloidea: Zoogonidae), a parasite

378 of the teleost fish Belone belone gracilis. Tissue and Cell 47:431-437.

379 Levron C, Miquel J, Oros M, Scholz T. 2010. Spermatozoa of tapeworms (Platyhelminthes, 380 Eucestoda): advances in ultrastructural and phylogenetic studies. Biological Reviews 85:523-543.

381 Levron C, Ternengo S, Marchand B. 2003. Ultrastructure of spermiogenesis and the 382 spermatozoon of Helicometra fasciata (Digenea, Opecoelidae), a parasite of Labrus merula 383 (Pisces, Teleostei). Acta Parasitologica 48:255-264.

384 Levron C, Ternengo S, Marchand B. 2004. Ultrastructure of spermiogenesis and the 385 spermatozoon of Monorchis parvus Looss, 1902 (Digenea, Monorchiidae), a parasite of 386 Diplodus annularis (Pisces, Teleostei). Parasitology Research 93:102-110.

387 Levron C, Ternengo S, Marchand B. 2004b. Spermiogenesis and sperm ultrastructure of 388 Poracanthium furcatum (Digenea, Opecoelidae), a parasite of Mullus surmuletus (Pisces, 389 Teleostei). Acta Parasitologica 49:190-200.

390 Madhavi R. 2008. Family Monorchiidae Odhner, 1911. In: Bray RA, Gibson DI, Jones A, eds. 391 Keys to the Trematoda, vol. 3. London: CAB International and The Natural History Museum, $392 \quad 145-175$.

393 Miquel J, Fournier-Chambrillon C, Fournier P, Torres J. 2006. Spermiogenesis and 394 spermatozoon ultrastructure of the cranial digenean Troglotrema acutum (Leuckart, 1842). 395 Journal of Parasitology 92:441-453.

396 Miquel J, Nourrisson C, Marchand B. 2000. Ultrastructure of spermiogenesis and the 
397 spermatozoon of Opecoeloides furcatus (Trematoda, Digenea, Opecoelidae), a parasite of Mullus 398 barbatus (Pisces, Teleostei). Parasitology Research 86:301-310.

399 Miquel J, Vilavella D, Świderski Z, Shimalov VV, Torres J. 2013. Spermatological 400 characteristics of Pleurogenidae (Digenea) inferred from the ultrastructural study of Pleurogenes 401 claviger, Pleurogenoides medians and Prosotocus confusus. Parasite 20:1-28.

402 Ndiaye PI, Bakhoum AJS, Sène A, Diagne PM, Miquel J. 2015a. The ultrastructural 403 characters of the mature spermatozoon of Opechona bacillaris (Molin, 1859) (Digenea, 404 Lepocreadiidae) a parasite of Scomber colias Gmelin, 1789 (Scombridae) off the coast of Dakar 405 (Senegal). Acta Zoologica (Stockholm) 96:91-98.

406 Ndiaye PI, Miquel J, Feliu C, Marchand B. 2003. Ultrastructure of spermiogenesis and 407 spermatozoa of Notocotylus neyrai González Castro, 1945 (Digenea, Notocotylidae), intestinal 408 parasite of Microtus agrestis (Rodentia: Arvicolidae) in Spain. Invertebrate Reproduction and 409 Development 43:105-115.

410 Ndiaye PI, Quilichini Y, Sène A, Bâ CT, Marchand B. 2011. Ultrastructure of the 411 spermatozoon of the digenean Cricocephalus albus (Kuhl \& van Hasselt, 1822) Looss, 1899 412 (Platyhelminthes, Pronocephaloidea, Pronocephalidae), parasite of "the hawksbill sea turtle" 413 Eretmochelys imbricata (Linnaeus, 1766) in Senegal. Zoologischer Anzeiger 250:215-222. 
414 Ndiaye PI, Quilichini Y, Sène A, Tkach VV, Bâ CT, Marchand B. 2012.Ultrastructural study

415 of the male gamete of Pleurogonius truncatus Prudhoe, 1944 (Platyhelminthes, Digenea, 416 Pronocephalidae) parasite of Eretmochelys imbricata (Linnaeus, 1766). Comptes Rendus 417 Biologies 335:239-246.

418 Ndiaye PI, Torres J, Eira C, Shimalov VV, Miquel J. 2015b. Ultrastructure of the 419 spermatozoon of the trematode Notocotylus noyeri (Digenea: Notocotylidae), a parasite of 420 Microtus arvalis (Rodentia: Cricetidae). Folia Parasitologica, 62:001.

421 Olson PD, Cribb TH, Tkach VV, Bray RA, Littlewood DTJ. 2003. Phylogeny and 422 classification of the Digenea (Platyhelminthes: Trematoda). International Journal for 423 Parasitology 33:733-755.

424 Quilichini Y, Foata J, Justine J-L, Bray RA, Marchand B. 2009. Sperm ultrastructure of the 425 digenean Siphoderina elongata (Platyhelminthes, Cryptogonimidae) intestinal parasite of 426 Nemipterus furcosus (Pisces, Teleostei). Parasitology Research 105:87-95.

427 Quilichini Y, Foata J, Justine J-L, Bray RA, Marchand B. 2010. Ultrastructural study of the 428 spermatozoon of Heterolebes maculosus (Digenea, Opistholebetidae), a parasite of the 429 porcupinefish Diodon hystrix (Pisces, Teleostei). Parasitology International 59:427-434.

430 Quilichini Y, Foata J, Justine J-L, Bray RA, Marchand. 2011a. Spermatozoon ultrastructure 431 of Gyliauchen sp. (Digenea: Gyliauchenidae), an intestinal parasite of Siganus fuscescens 432 (Pisces: Teleostei). Biological Bulletin 221:197-205.

433 Quilichini Y, Foata J, Justine J-L, Bray RA, Marchand B. 2011b. Sperm ultrastructure of 434 Helicometra epinepheli (Platyhelminthes, Digenea, Opecoelidae), parasite of Epinephelus 435 fasciatus (Pisces, Teleostei). Histology and Histopathology 26:1019-1028.

436 Quilichini Y, Foata J, Marchand B. 2007. Ultrastructural study of the spermatozoon of Nicolla 
437 testiobliquum (Digenea, Opecoelidae) parasite of brown trout Salmo trutta (Pisces, Teleostei).

438 Parasitology Research 101:1295-1301.

439 Quilichini Y, Foata J, Orsini A, Marchand B. 2007. Spermiogenesis and spermatozoon

440 ultrastructure of Nicolla wisniewskii (Digenea: Opecoelidae), an intestinal parasite of brown trout

441 Salmo trutta (Pisces: Teleostei). Journal of Parasitology 93:469-478.

442 Quilichini Y, Ndiaye PI, Sène A, Justine JL, Bray RA, Tkach VV, Bâ CT, Marchand B.

443 2015. Ultrastructural characters of the spermatozoa in Digeneans of the genus Bianium Stunkard,

4441930 (Digenea, Lepocreadiidae) parasites of fishes: a comparative study of Bianium plicitum and

445 Bianium arabicum. Parasitology Research 114:3747-3757.

446 Reynolds ES. 1963. The use of lead citrate at high $\mathrm{pH}$ as an electron-opaque stain in electron

447 microscopy. Journal of Cell Biology 17:208-212.

448 Seck MT, Marchand B, Bâ CT. 2008. Spermiogenesis and sperm ultrastructure of Carmyerius 449 endopapillatus (Digenea, Gastrothylacidae), a parasite of Bos taurus in Senegal. Acta 450 Parasitologica 53:9-18.

451 Ternengo S, Quilichini Y, Katharios P, Marchand B. 2009. Sperm ultrastructure of the gall

452 bladder fluke Anisocoelium capitellatum (Digenea: Cryptogonimidae), a parasite of Uranoscopus 453 scaber (Pisces: Uranoscopidae). Parasitology Research 104:801-807.

454 Thiéry JP. 1967. Mise en évidence des polysaccharides sur coupes fines en microscopie 455 électronique. Journal of Microscopy 6:987-1018.

456 Yang M-Y, Dong H-F, Jiang M-S. 2003. Ultrastructural observation of spermatozoa and 457 fertilization in Schistoma japonicum. Acta Tropica 85:63-70.

458 Zhukova MV, Mordvinov VA, Kiseleva E. 2014. Ultrastructure of spermatozoa in the seminal 459 receptacle of the liver fluke Opisthorchis felineus (Rivolta, 1884). Parasitology Research 
460 113:1093-1101. 


\section{Figure 1 (on next page)}

Cross-sections of the mature spermatozoon of Opisthomonorchis dinema observed in TEM.

(A) Region I showing the anterior extremities of the two axonemes, the external ornamentation and cortical microtubules; (B and C) middle part of the region I exhibiting (B) both formed axonemes, the external ornamentation associated with cortical microtubules, spine-like body and attachment zones (C); (D and E) posterior part of the region I characterized by the appearance of the first mitochondrion and the cortical microtubule; ( $\mathbf{F}$ and $\mathbf{G}$ ) region II or transitional areas showing (F) the posterior part of the first mitochondrion, the axonemes and a decreasing number of cortical microtubules from about 10 to 5; $\mathbf{~ H ) ~ a n t e r i o r ~ p a r t ~ o f ~ t h e ~ r e g i o n ~ I I I ~ c h a r a c t e r i z e d ~ b y ~ t h e ~ d i s o r g a n i z a t i o n ~ o f ~ t h e ~}$ first axoneme; (I) middle part of the region III characterized by the appearance of the second mitochondrion and the nucleus; (J) posterior part of the region III characterized by only the nucleus, one axoneme and cortical microtubules; ( $\mathbf{K}$ and $\mathbf{L}$ ) region IV corresponding to the posterior spermatozoon extremity. Note the disorganization of the second axoneme (K). Scale bars: $0.2 \mu \mathrm{m}$. Arrowheads indicate attachment zones. Aae1: anterior extremity of first axoneme; Aae2: anterior extremity of second axoneme; $\mathrm{Cm}$ : cortical microtubules; Eo: external ornamentation of the plasma membrane; M1: first mitochondrion; M2: second mitochondrion; N: nucleus; Pae1: posterior extremity of axoneme 1; S: singlet of microtubule; Sb: spine-like body. 
(A) Aas1 J

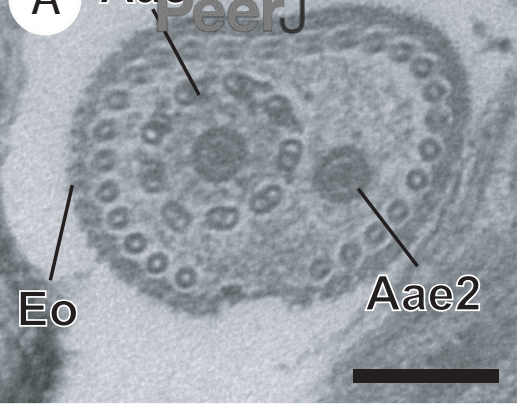

(D)

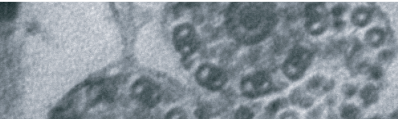

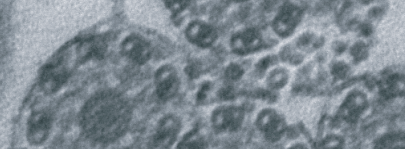

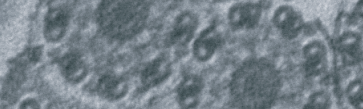

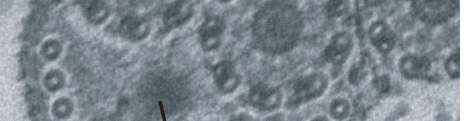
$301000 \%=$ 倠o $\mathrm{M1}$

G $609 \log ^{2}$ 20.

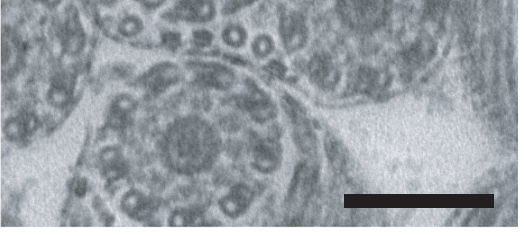

(1)

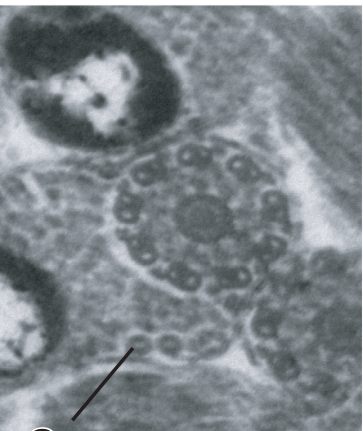

(B) Eo

$\mathrm{cm}$
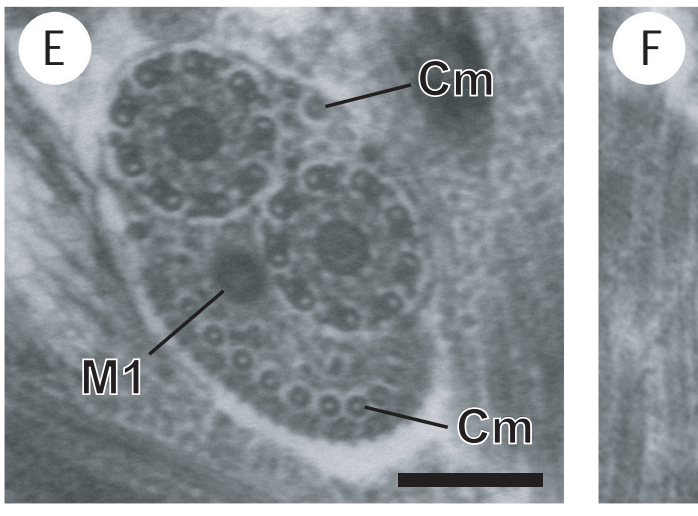

cm
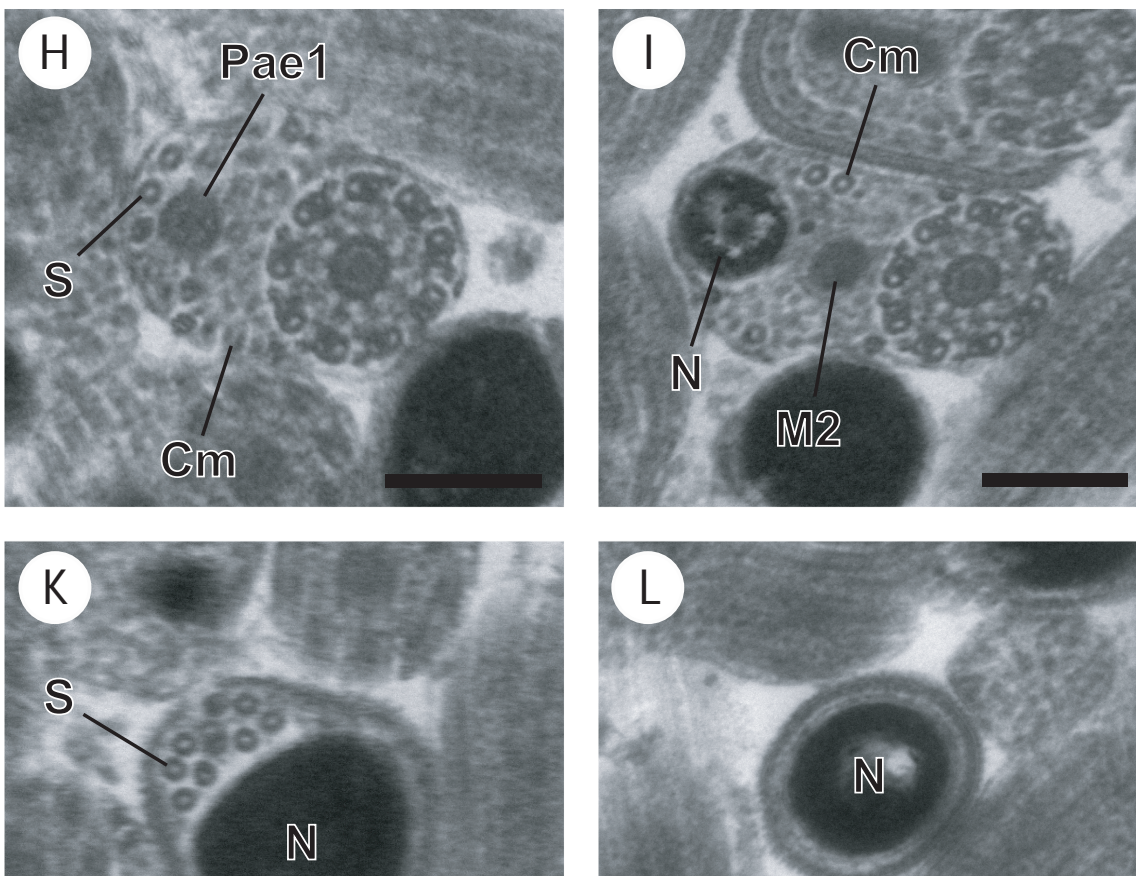

(L)

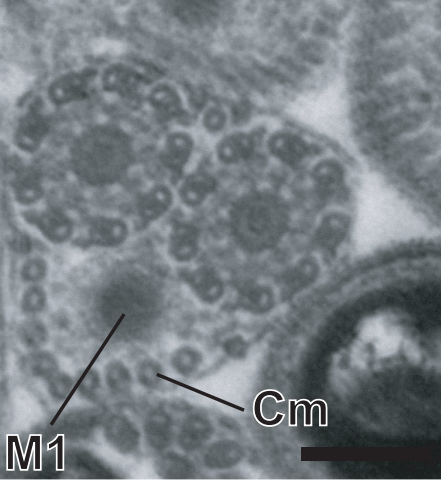

ChPeer) reviewing PDF | (2016:06:11566:1:0:NEW 24 Aug 2016) 


\section{Figure 2 (on next page)}

Regions I-III of mature spermatozoon of Paramonorcheides selaris observed in TEM.

(A-C) Longitudinal and cross-sections of region I corresponding to the anterior spermatozoon extremity; (D) longitudinal section in the ornamented area showing the spine-like body interrupting the external ornamentation of the plasma membrane; cross-section in the posterior part of the region I characterized by the appearance of the first mitochondrion; ( $\mathbf{F}$ and $\mathbf{G}$ ) consecutive cross-sections in region II or transitional area showing only the axonemes, the first mitochondrion and a decrease of the cortical microtubules number; $\mathbf{( H )}$ anterior part of region III exhibiting the second mitochondrion; (I and J) cross-sections of middle part of region III showing the appearance of the nucleus. Note the disorganisation of the first axoneme (J). Scale bars: $0.2 \mu \mathrm{m}$. Aae2: anterior extremity of second axoneme; Ase: anterior spermatozoon extremity; Ax1: first axoneme; Ax2: second axoneme; $\mathrm{Cm}$ : cortical microtubules; Eo: external ornamentation of the plasma membrane; M1: first mitochondrion; M2: second mitochondrion; N: nucleus; Pae1: posterior extremity of the first axoneme; Sb: spine-like body. 


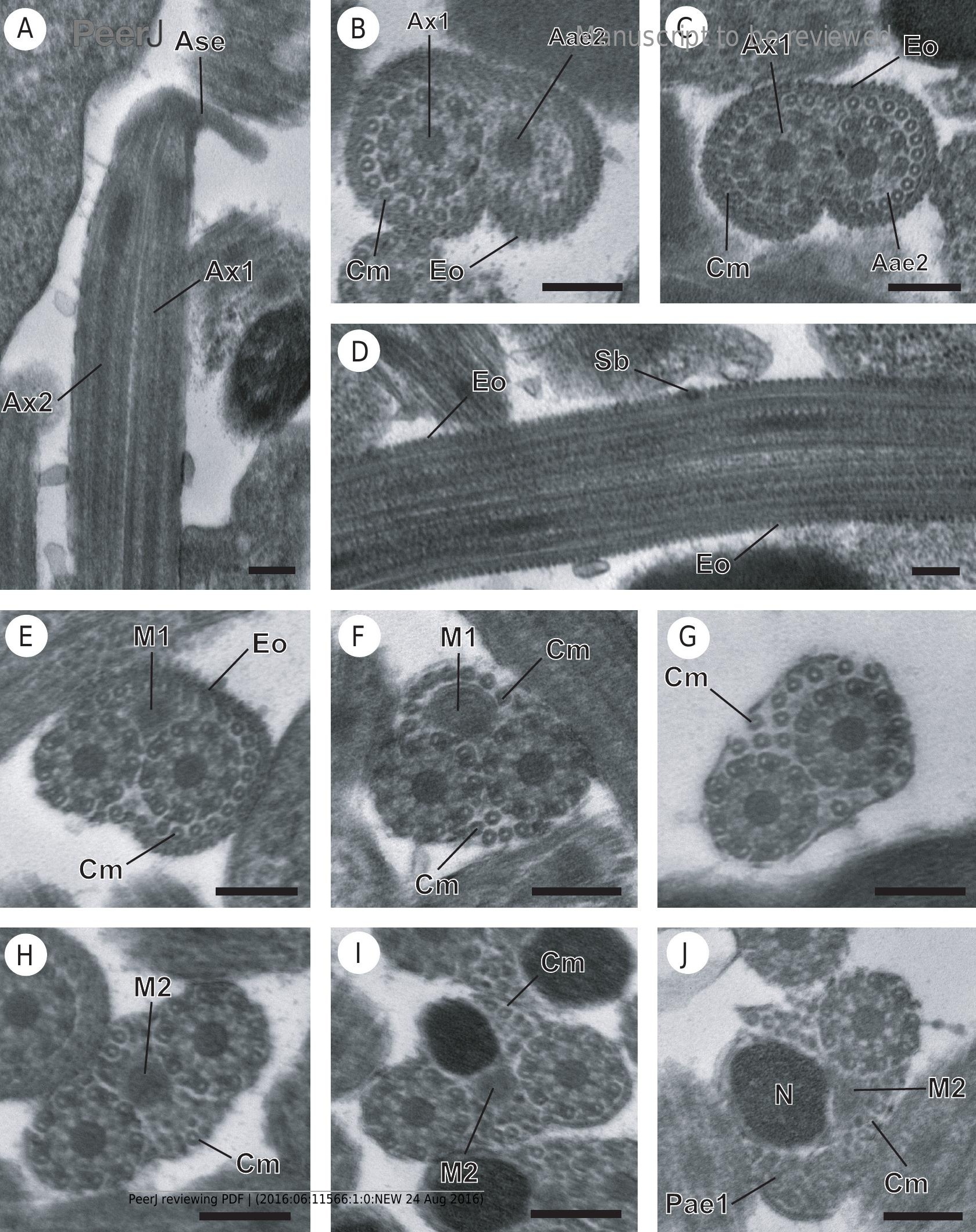




\section{Figure 3 (on next page)}

Cross-section of regions III and IV of the mature spermatozoon of Paramonorcheides selaris observed in TEM.

(A) Posterior part of the region III characterized by the nucleus, the second axoneme, the second mitochondrion and cortical microtubules; (B and C) region IV characterized by the nucleus, the second axoneme which disorganizes progressively, and the posterior extremity of the last cortical microtubules; (D) posterior part of region IV containing only the nucleus; (E) positive test of Thiéry for labelling of glycogen. Scale bars: $0.2 \mu \mathrm{m}$ (A-D), $0.5 \mu \mathrm{m}$ (E). Cm: cortical microtubules; $\mathrm{D}$ : doublets of microtubule; Eo: external ornamentation of the plasma membrane; G: granules of glycogen; M2: second mitochondrion; N: nucleus. 


\section{A}

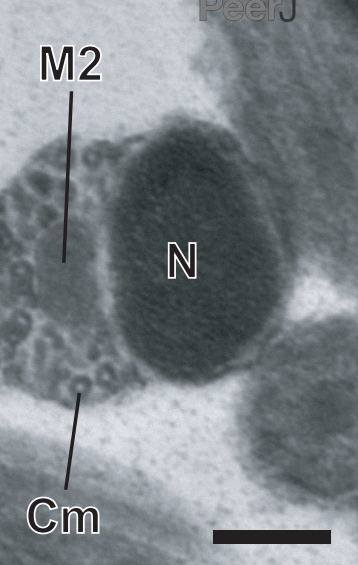

\section{(D)}
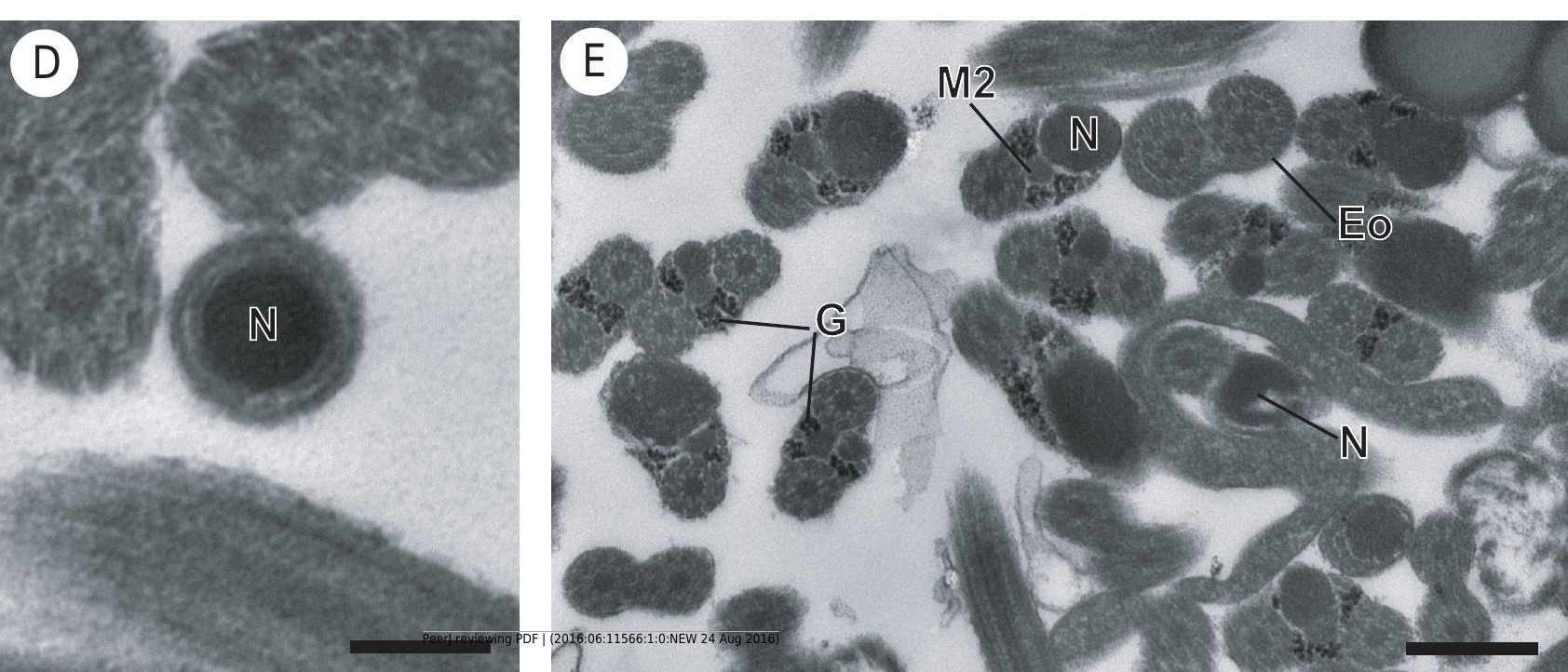

Cm

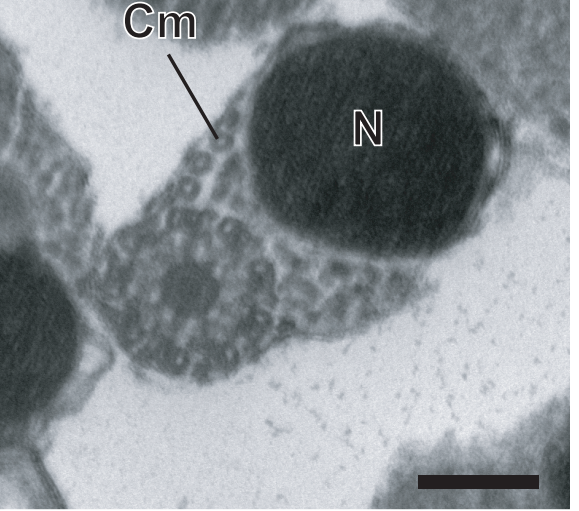

$\frac{2}{6}$
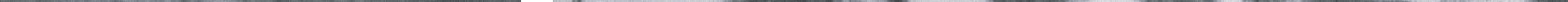


\section{Figure 4 (on next page)}

Comparative schematic reconstruction of the mature spermatozoa of Opisthomonorchis dinema (a) and Paramonorcheides selaris (b).

Aae1: anterior extremity of first axoneme; Aae2: anterior extremity of second axoneme; Ase: anterior spermatozoon extremity; Ax1: first axoneme; Ax2: second axoneme; Az: attachment zone; $\mathrm{Cm}$ : cortical microtubules; Eo: external ornamentation of the plasma membrane; $\mathrm{G}$ : granules of glycogen; M1: first mitochondrion; M2: second mitochondrion; N: nucleus; Pae1: posterior extremity of the first axoneme; Pae2: posterior extremity of the second axoneme; Pm: plasma membrane; Pse: posterior spermatozoon extremity; Sb: spine-like body. 

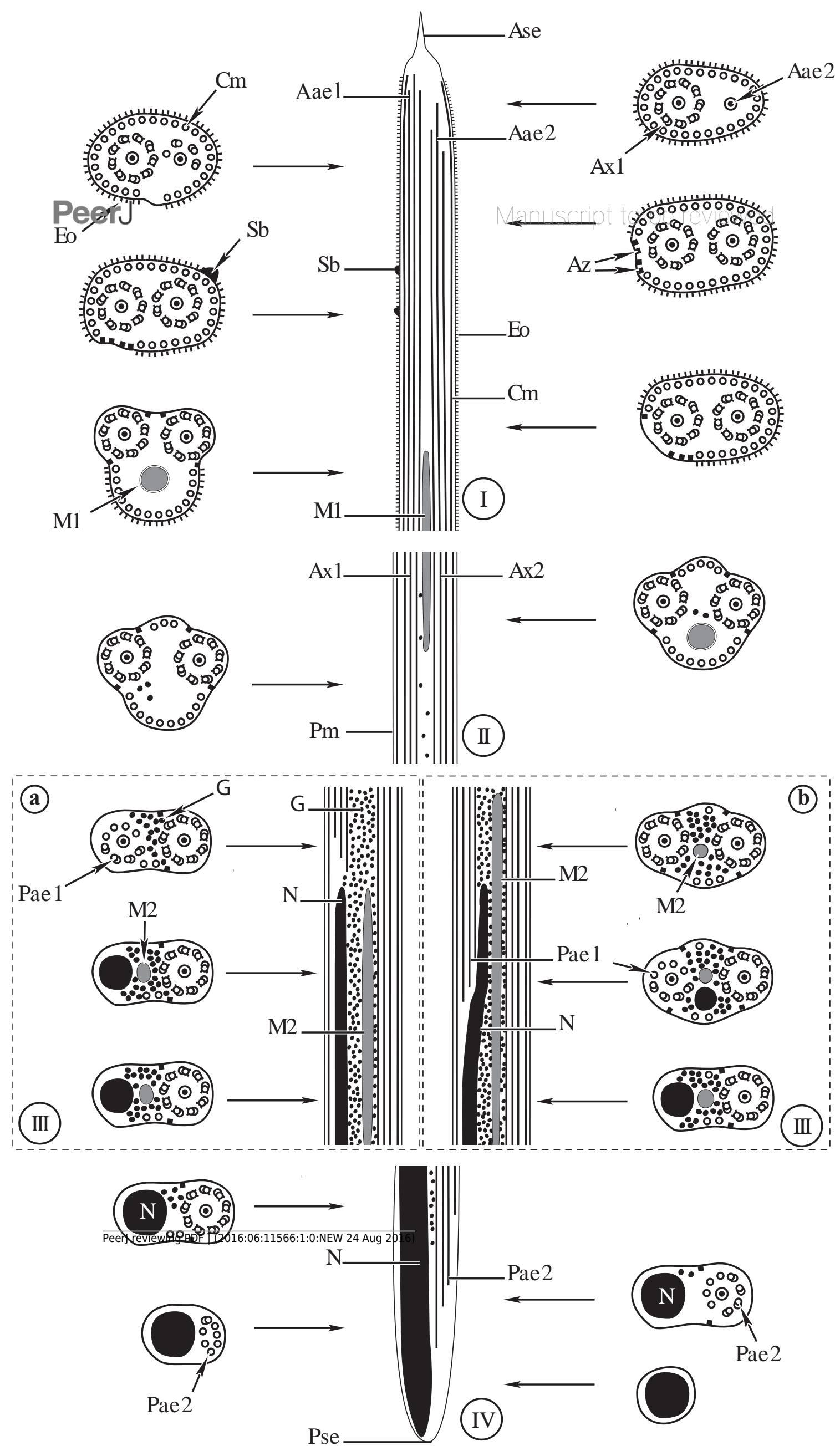


\section{Table $\mathbf{1}$ (on next page)}

Comparative ultrastructural characteristics of the spermatozoon in the Monorchiidae.

Ase, anterior spermatozoon extremity; $\mathrm{Ax}$, axoneme; $\mathrm{Cm}$, cortical microtubules; Edm, electron-dense material; Eo, external ornamentation of the plasma membrane; $M$, number of mitochondria; MCm, maximum number of cortical microtubules; N, nucleus; TAx, type of axoneme; TEo, type of external ornamentation according to Quilichini et al. (2011a); Psc, posterior spermatozoon character; Sb, spine-like bodies; +/-, presence/absence of considered character. 
1

\begin{tabular}{|l|c|c|c|c|c|c|c|c|c|}
\hline Parasites species & \multicolumn{7}{|c|}{ Spermatological characteristics } & \multicolumn{2}{c|}{ References } \\
\cline { 2 - 9 } & TAx & Ase & Eo & TEo & Sb & MCm & M & Psc & \\
\hline Helicometroides atlanticus & $9+“ 1 ”$ & $2 \mathrm{Ax}+\mathrm{Edm}$ & + & 2 & - & 35 & 2 & $\mathrm{~N}$ & Diagne et al. (2015) \\
\hline Monorchis parvus & $9+$ “1” & $2 \mathrm{Ax}+\mathrm{Eo}$ & + & 1 & - & 25 & 2 & $\mathrm{~N}$ & Levron et al. (2004a) \\
\hline Opisthomonorchis dinema & $9+“ 1 ”$ & $2 \mathrm{Ax}+\mathrm{Eo}$ & + & 1 & + & 28 & 2 & $\mathrm{~N}$ & Present study \\
\hline Paramonorcheides selaris & $9+“ 1 ”$ & $2 \mathrm{Ax}+\mathrm{Eo}$ & + & 1 & + & 26 & 2 & $\mathrm{~N}$ & Present study \\
\hline
\end{tabular}

2 